\title{
NOVĚ NALEZENÝ POSUDEK ALBERTA EINSTEINA NA PRÁCI JULIA SUCHÉHO O TEPELNÉM ZÁŘENÍ
}

\author{
JANA RATAJOVÁ
}

DOI: $10.14712 / 23365730.2019 .21$

V loňském roce byly Archivu UK předloženy k posouzení dvě písemnosti týkající se habilitace českého fyzika Julia Suchého, které byly v soukromém vlastnictví rodiny. Jedná se o posudek A. Einsteina na práci Julia Suchého o tepelném záření, která vyšla v časopise „Annalen der Physik“, a zprávu profesora H. A. Lorentze o činnosti Julia Suchého na univerzitě v Leidenu. Einsteinův posudek byl vyhotoven prímo na žádost Suchého a ten si zřejmě ponechal jeho originál. Zda byl v habilitačním spise uložen nějaký opis, není dnes možné zjistit, protože v archivu ČVUT se habilitační spis Julia Suchého nedochoval. ${ }^{1}$ Oba dokumenty byly v červnu 2019 prodány. Majitelka těchto písemností souhlasila před prodejem s publikováním obou dokumentů, které zajímavým způsobem vypovídají nejen o Einsteinově pobytu v Praze, ${ }^{2}$ ale také o kontaktech mezi českou a německou vědeckou obcí i o napojení českých fyziků na špičková evropská pracoviště. K témuž přispívají i dopisy J. Suchého H. A. Lorentzovi zveřejněné v závěru příspěvku E. Těšínské. ${ }^{3}$

\section{Ediční poznámka:}

Dokumenty byly v souladu s obecně přijatými doporučeními pro novověké německé texty transkribovány, tedy přepsány podle dnešních pravopisných zásad. ${ }^{4}$ To se týká především interpunkce a grafické stránky textu (např. psaní ss a $\beta$, psaní velkých/malých písmen, velkých umlautů apod.), modernizačních zásahů však bylo třeba poměrně málo. Oba texty jsou psány latinkou a nikoliv $v$ té době ještě běžným kurentem. Edice je opatřena českým překladem a doplněna fotografiemi editovaných dokumentů.

Za informaci děkuji dr. E. Těšínské.

2 Albert Einstein působil v Praze od letního semestru 1911 do letního semestru 1912, posudek pochází tedy až ze samého konce jeho pražského působení. K Einsteinovu pobytu v Praze se váže rozsáhlá bibliografie, za všechny lze jmenovat alespoň př́ispěvek Jana Havránka dokumentující nemnohé materiály svázané s Einsteinovým pražským pobytem uložené v univerzitním archivu: Jan HAVRÁNEK, Materiály k Einsteinovu pražskému působení z Archivu Univerzity Karlovy, AUC-HUCP 20/1, 1980, s. 109-134.

3 Příspěvek Emilie Těšínské v tomto svazku se věnuje Juliu Suchému a jeho habilitaci podrobněji.

4 Ivan ŠŤovíčEK a kol., Zásady vydávání novověkých historických pramenů z obdobi od počátku 16. století do současnosti, Praha 2002, s. 61. 


\section{Posudek Alberta Einsteina na práci Julia Suchého o tepelném záření, 15. 7. 1912}

Rukopis, 2 strany, razitko Ústavu pro teoretickou fyziku německé Karlo-Ferdinandovy Univerzity v Praze

Herr Dr. J. Suchý ersuchte mich darum, ich möge ein kurzes Gutachten über seine in den „Annalen der Physik“ publizierte Arbeit „Wärmestrahlung und Wärmeleitung“5 abgeben. Dieser Aufforderung komme ich gerne mit den folgenden Zeilen nach.

Das behandelte Problem liegt in der Frage: Welchen Anteil hat die Wärmestrahlung neben der molekularkinetisch übertragenen Wärme bei Vorgängen der Wärmeleitung? Ausgehend von den elektromagnetischen Grundgleichungen wird dargethan, dass es zwei Arten scheinbarer Wärmeleitung durch Strahlung gibt, die wohl auseinanderzuhalten sind. Bei der Übertragung der ersten Art haben wir es mit Zustrahlungen solcher Volumelemente zu thun, die hinreichend weit voneinander etnfernt sind, um die Ausbreitung der Strahlung als gradlinig ansehen zu können; ausserdem besteht aber eine Übertragung (zweiter Art) zwischen derart benachbarten Volumelementen, dass man mit der Hypothese gradliniger Ausbreitung nicht operieren darf.

Es wird gezeigt, dass sich die Ausbreitung erster Art ohne Zusatzhypothesen berechnen lässt. Dabei zeigt sich, dass bei Metallen, überhaupt bei stark absorbierenden Körpern diese Art der Ausbrei der Wärme einen verschwindend kleinen Beitrag zur gesamten Wärmeleitfähigkeit liefert. Anderseits zeigt sich aber, dass diese Übertragung erster Art weitaus die wichtigste Rolle spielt bei der Wärmeübertragung in mächtigen Gasschichten. Die Rechnung ist speziell für Kohlensäure durchgeführt.

Bei der Untersuchung der Ausbreitung zweiter Art (Zustrahlung sehr nahe benachbarter Volumteile) wird man auf ein räumliches Integral geführt, dessen Integrationsgrenzen davon abhängen, welches [!] die kleinste Entfernung $v_{0}$ ist, auf welche Volumteilchen der Materie noch Energie durch Strahlung austauschen. Da jenes Integral unendlich wird, wenn $v_{0}=0$ gesetzt wird, und eine exakte Ermittelung von $v_{0}$ unmöglich ist, so ist jene Ausbreitung 2. Art auch nicht exakt berechenbar. Der Beitrag, den die Ausbreitung zweiter Art zu der gesamten Wärmeleitung in stark absorbierenden Körpern, wie Metallen, beisteuert, kann aber erheblich werden und - wie in der Arbeit motiviert wird - zur Erklärung der Abweichungen vom Wiedemann-Franz'schen Gesetze herangezogen werden. Entnimmt man hypothetisch jenen Abweichungen den durch die Strahlungsvorgänge (2. Art) gelieferten Beitrag zum gesamten Wärmeleitvermögen, so kann man - wie der Verfasser zeigt hieraus umgekehrt $v_{0}$ berechnen und erhält dafür interessanter Weise eine der Grössenordnung nach mit dem Abstand benachbarter Moleküle übereinstimmende Länge. Leider ist eine weiter gehende Vergleichung der Theorie mit dem Experiment unmöglich, weil nur die gesamte Wärmeleitung, nicht aber der durch Strahlung bewirkte Bruchteil derselben, bei stark absorbierenden Körpern (falls die Übertragung 2. Art überwiegt) Gegenstand der Erfahrung sein kann. Es können also über den Inhalt der Arbeit hinausgehende Prüfungen der Theorie dem Experiment nicht erhofft werden.

Wenn auch die Methoden, die in der Arbeit angewendet sind, von H. A. Lorentz herrühren, so bedurfte doch die Durchführung der Arbeit einer bemerkenswerten Beherrschung der modernen Elektrodynamik und einer anzuerkennenden geistigen Energie. Neu an den

5 Suchého práce vyšla roku 1911 (viz příspěvek E. Těšínské a jeho obrazová příloha). 
Resultaten der Arbeit ist insbesondere die Berechnung der Grössenordnung der Strahlungsübertragung zweiter Art, dies [!] Resultat ist für die Auffassung der Wärmeleitung von unbestreitbarer Bedeutung.

Prag 15. VII 12

A. Einstein

Institut für theoretische Physik an der k. k. deutschen Universität in Prag

\section{Přreklad do češtiny}

Pan dr. J. Suchý mne požádal, abych vyhotovil krátký posudek na jeho práci „Tepelné záření a vedení tepla“, publikovanou v „Annalen der Physik“. Této žádosti rád vyhovuji prostřednictvím následujících řádků.

Pojednávaný problém spočívá $\mathrm{v}$ otázce: Jaký je podíl tepelného záření vedle molekulárně-kinetického přenosu tepla $\mathrm{v}$ procesech vedení tepla? Vycházeje ze základních elektromagnetických rovnic, autor dovozuje, že existují dva druhy zjevného vedení tepla prostřednictvím záření, které je patrně nutno rozlišovat. Při přenosu prvního druhu máme co do činění s vyzařováním takových objemových elementů, které jsou od sebe dostatečně vzdáleny na to, abychom šiřrení záření mohli považovat za prímočaré; kromě toho ale existuje prenos (druhého typu) mezi těmito sousedními objemovými elementy, takže s hypotézou př́močarého šíření nemůžeme pracovat.

Autor ukazuje, že šíření prvního typu lze vypočítat bez dodatečných hypotéz. Přitom se ukazuje, že u kovů a vưbec u silně absorbujících těles má tento druh šiření tepla mizivě zanedbatelný podíl na celkové tepelné vodivosti. Na druhou stranu se ale ukazuje, že tento přenos prvního typu hraje zdaleka nejvýznamnějši roli při přenosu tepla v mocných vrstvách plynu. Je proveden výpočet speciálně pro kyselinu uhličitou. ${ }^{6}$

Při studiu šíření druhého typu (vyzařování velmi blízce sousedících objemových dílů) dospějeme $\mathrm{k}$ integrálu, jehož integrační hranice závisejí na tom, jaká je nejmenší vzdálenost $v_{0}$, na niž si ještě objemové dílky hmoty vyměňují energii zářením. Jelikož je tento integrál nekonečný, pokud platí, že $v_{0}=0$, a přesné zjištění $v_{0}$ není možné, tak ani toto šíření druhého typu nelze exaktně spočítat. Míra, kterou se šíření druhého typu podílí na celkovém vedení tepla v silně absorbujících tělesech, jako jsou kovy, může být ale značná $\mathrm{a}$ - jak je $\mathrm{v}$ práci dovozeno - může být využita $\mathrm{k}$ vysvětlení odchylek od Wiedemannova-Franzova zákona. Odstraníme-li hypoteticky z těchto odchylek onen podíl, kterým se procesy záŕení (2. typu) podílejí na celkové tepelné vodivosti, tak z toho lze - jak autor dovozuje - zpětně vypočítat $v_{0}$ a obdrží se, což je zajímavé, délka řádově shodná se vzdáleností sousedících molekul. Zevrubnější srovnání teorie s experimentem není bohužel možné, protože předmětem pozorování může být jen celkové vedení tepla, nikoliv samotná jeho část způsobená zářením, u silně absorbujících těles (pokud převažuje přenos 2. typu). Další testování teorie experimentem, jež by přssahovalo rámec této práce, nelze proto očekávat.

6 Zřejmě Einsteinovo přehlédnutí, v Suchého práci jsou výsledky pro oxid uhličitý. Za upozornění děkuji E. Těšínské. 
I když metody použité $\mathrm{v}$ této práci pocházejí od $\mathrm{H}$. A. Lorentze, provedení této práce vyžadovalo v pozoruhodné míře zvládnutí moderní elektrodynamiky a obdivuhodnou duševní energii. Nové mezi výsledky práce je zejména spočítání řádové velikosti přenosu záření druhého typu, tento výsledek má nepopiratelný význam pro pochopení vedení tepla.

Praha 15. 7. 1912

A. Einstein

Ústav teoretické fyziky na c. k. německé univerzitě v Praze

Zpráva H. A. Lorentze, profesora univerzity v Leidenu o činnosti Julia Suchého (pravděpodobně príloha žádosti o stipendium), Leiden, 18. 5. 1905. Rukopis, kolek a razítko Filozofické fakulty české c.k. univerzity v Praze.

Herr Dr. Julius Suchý hat den ihm verliehenen Urlaub dazu benutzt, verschiedene Gebiete der Physik unter meiner Leitung gründlich und mit grossem Fleiss zu studieren, und sich zu einer selbständigen wissenschaftlichen Untersuchung vorzubereiten, die er, wie ich hoffe, wenn ihm genügende Zeit gelassen wird, mit gutem Erfolg wird vollenden können.

H. A. Lorentz

Professor an der Universität Leiden

Leiden, 18. Mai 1908

Pan doktor Julius Suchý využil svou dovolenou k tomu, aby pod mým vedením důkladně a s velkou pílí studoval různé oblasti fyziky a připravoval se na samostatný vědecký výzkum, který, jak doufám, pokud mu bude dopřán dostatek času, bude moci s úspěchem zakončit.

H. A. Lorentz

Profesor na univerzitě v Leidenu Leiden, 18. května 1908 


\section{Obrazová príloha}

Hevr tr, I. Suchy ersuchte mich darum, ich noge ein kros Gutachter viber seire in den, Amolen

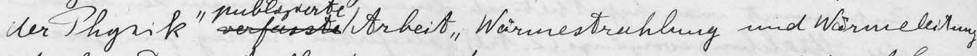

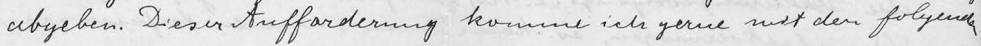
Zilen nach. -

Das behandelte Tublens hugt me der Traje: Whlohen

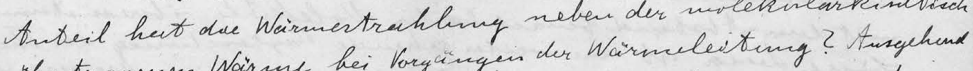

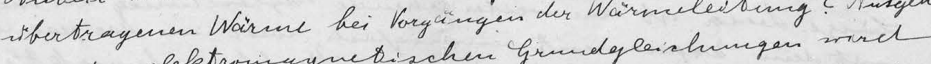

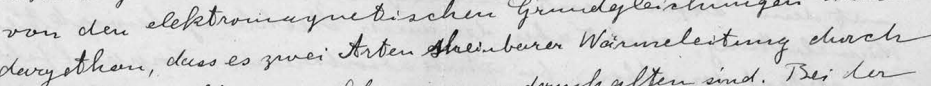

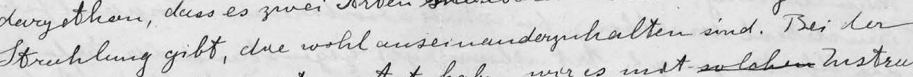

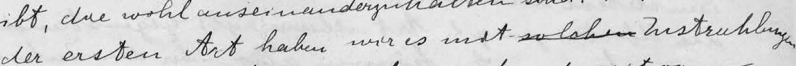
solcher Volumelemente se thrme, ue himeschend wert on

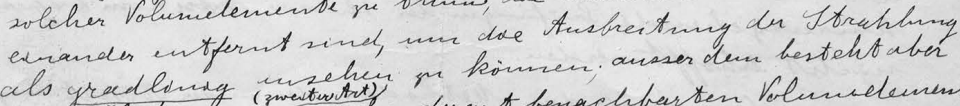

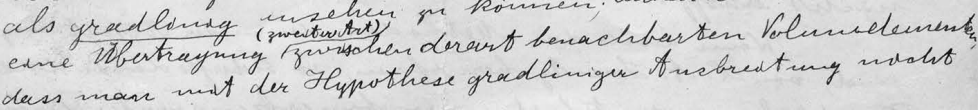
Mperveren deuf.

Es word gegeigt, duss sich die Anstreitny erster Art chre Zusatghypothisen berechnen lisst. Oabei gevgt sech,

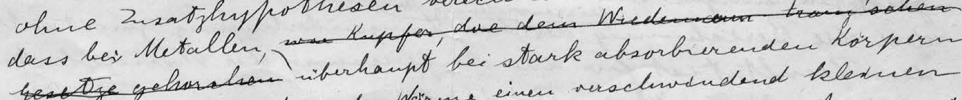

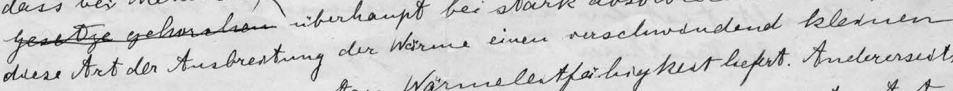

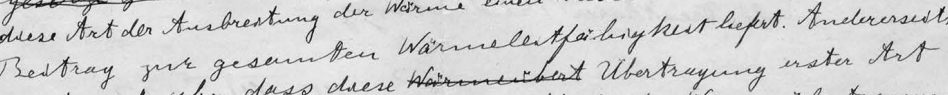

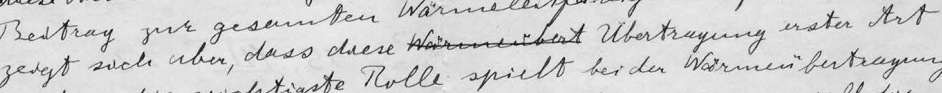

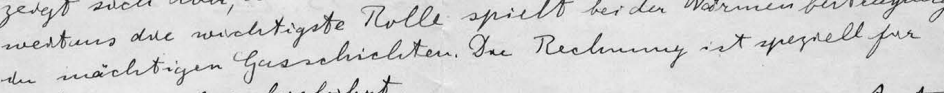
kohbusaive entclygforhet.

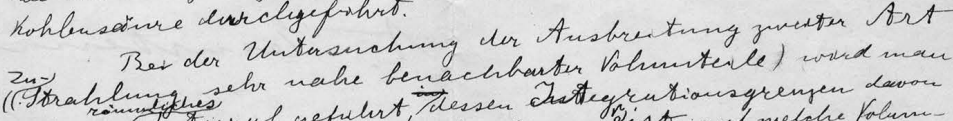

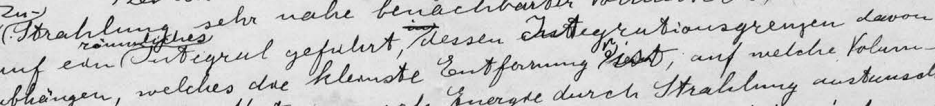

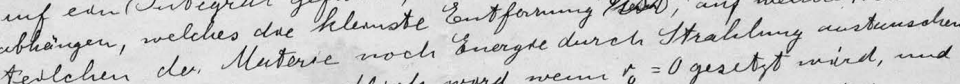

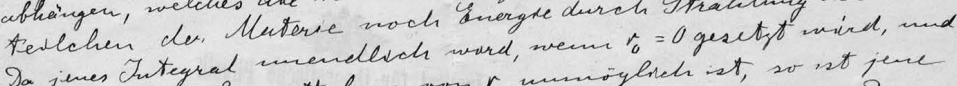

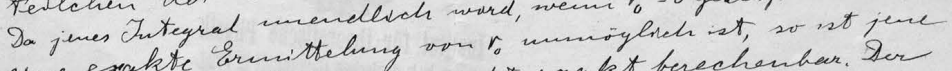

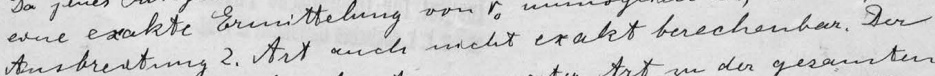

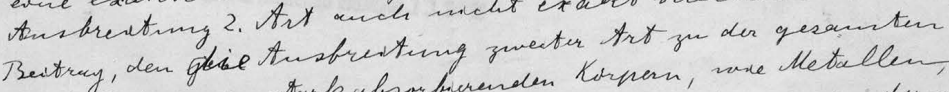
Warmilettung in stark absorbuenden Kirpan, sare Metallen,

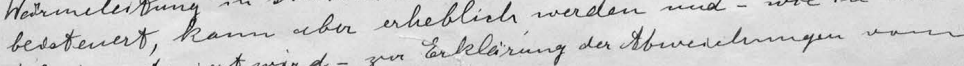

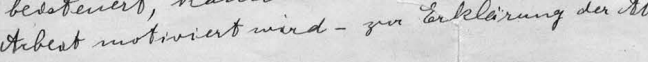

Obr. 1 První strana posudku Alberta Einsteina na práci Julia Suchého o tepelném záření 
Wredenuann - Trang schen cgesetze herangegogen werden-

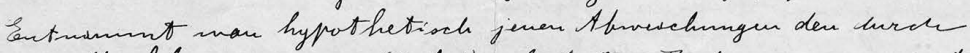

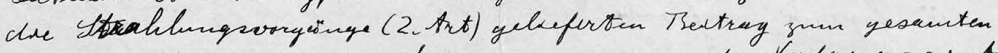
Warmelentormigen, so kanm man - noe der Vorfasoer jergt-

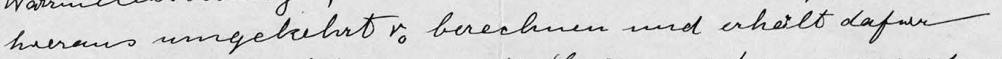
suteressanter Weire ene der Groissuardming neech mat den Abstand fenachbarter Avlebirle iberenstimmende Lainge. Lesder ist ene wenter yehende torgeeschineg der theome

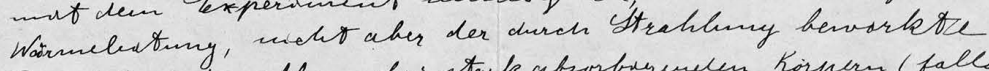
Bunchted derselben, bei stark aborbirenelen koipen ( falls de Vibertruyng 2. Art ibermagt) Gegustand der Gerfahreng

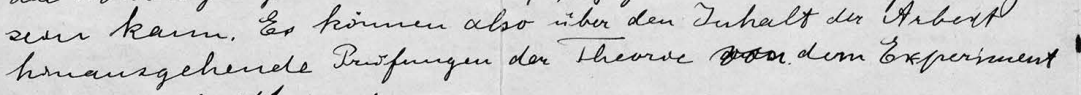
wacht erhoff tiverden. -

Wene andh dere Methoden, dre un der Strtent angeniendex

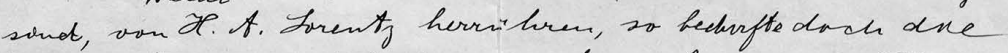

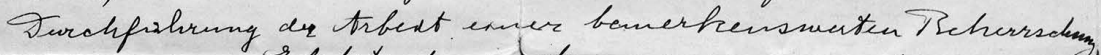

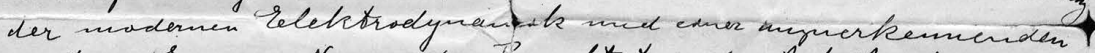
geistigen Enoryar. Nen an deu Fesultaten der Arbent ist insbeson.

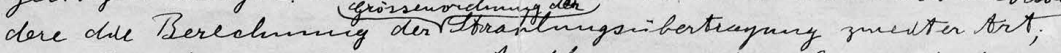
dues Resultat ist fier dne Anffassung der Woincrelesting von nubestrenthurer Tedenting
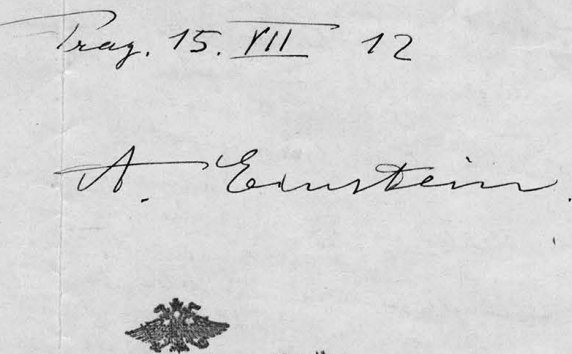

Institut fïr theoretische Physllk

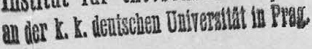

Obr. 2 Druhá strana posudku Alberta Einsteina na práci Julia Suchého o tepelném záření 

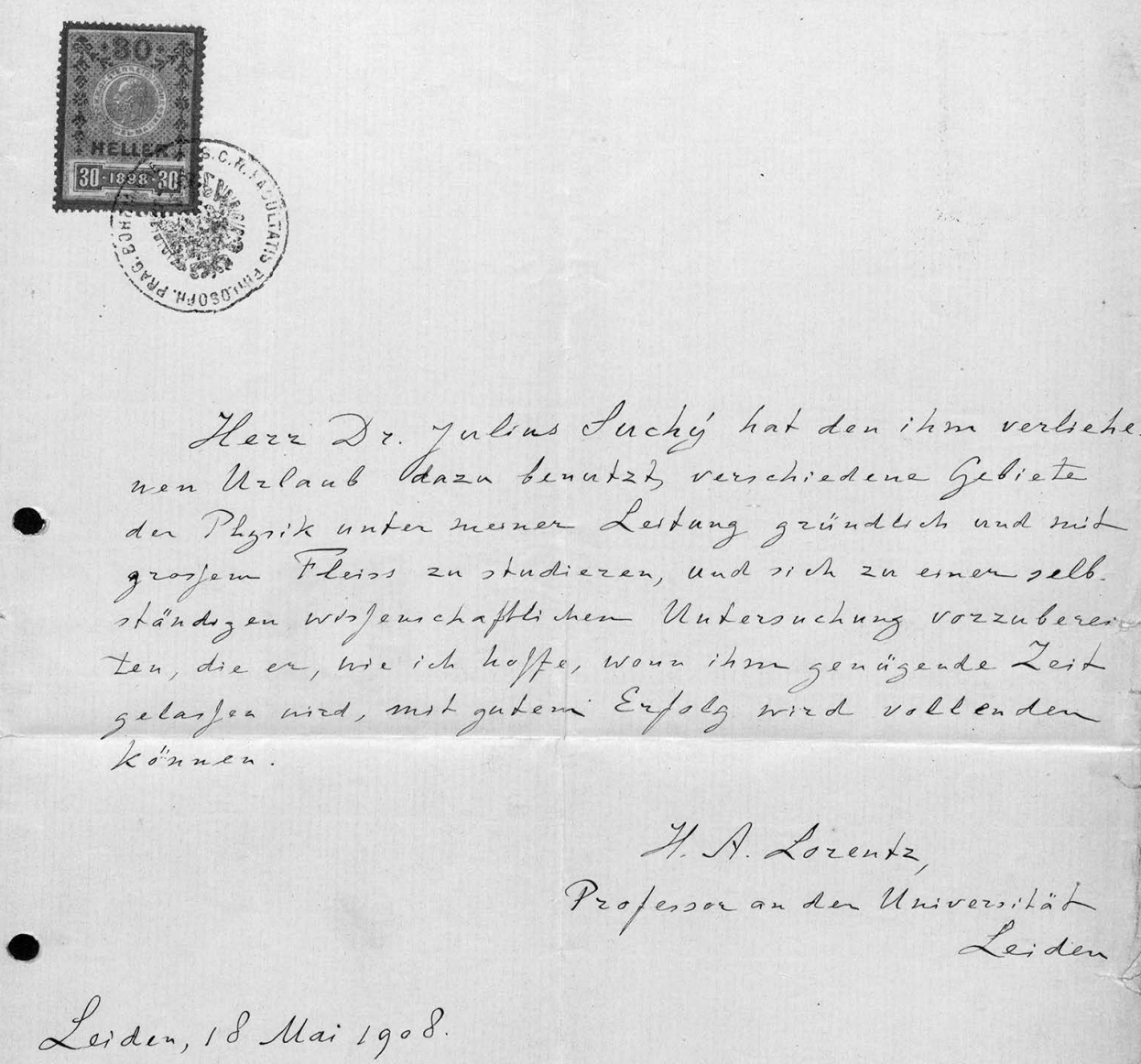

Obr. 3 Zpráva H. A. Lorentze o činnosti Julia Suchého 